\title{
Optimisation in Forest Management
}

\author{
Abdulğaffar Kaya ${ }^{1}$ - Pete Bettinger ${ }^{2} \cdot K_{\text {Kevin Boston }}{ }^{3} \cdot$ Ramazan Akbulut $^{2}$. \\ Zennure Ucar $^{2} \cdot$ Jacek Siry $^{2} \cdot$ Krista Merry $^{2} \cdot$ Chris Cieszewski $^{2}$
}

Published online: 17 February 2016

(C) Springer International Publishing AG 2016

\begin{abstract}
The field of forestry has employed various computer-assisted optimisation approaches since the early 1960s to address the efficient allocation of resources towards various forest management objectives. These approaches continue to evolve, and in the last 5 years, the research has expanded to demonstrate how complex, non-linear relationships can be recognised and incorporated into planning processes at the tree, stand, forest and landscape levels. In addition to an overview of the use of optimisation in forestry, we provide an examination of work published in the last 5 years from 30 international journals, worldwide, which consistently publish forestry and natural resource management research papers. Through this review, we found that landscape-level optimisation is a relatively new and expanding area of research, most often performed by one large public landowner in regions
\end{abstract}

This article is part of the Topical Collection on Forest Management

Pete Bettinger

pbettinger@warnell.uga.edu

Abdulğaffar Kaya

abdulgaffarkaya@gmail.com

Kevin Boston

Kevin.Boston@oregonstate.edu

Ramazan Akbulut

rmznakbulut@gmail.com

Zennure Ucar

zennucar@uga.edu

Jacek Siry

jsiry@uga.edu where the resulting plan of action has an effect on all landowners and resources. We also note that at the forest level, exact methods for optimising systems mainly continue to be used, and at the stand level, optimisation seems to now involve exploration of a variety of analytical methods. A large portion of the recent research in the optimisation of forest management have involved European forests, which is a function of large public ownership of land and the tradition and requirements for management planning, and roughly half of the effort has arisen from researchers located in Nordic countries (Denmark, Finland, Norway and Sweden).

Keywords Operations research - Mathematical programming $\cdot$ Planning $\cdot$ Linear programming $\cdot$ Optimisation
Krista Merry

kmerry@warnell.uga.edu

Chris Cieszewski

biomat@uga.edu

1 Graduate School of Agriculture, Division of Forest and Biomaterial Science, Forest Resources and Society, Kitashirakawa Oiwake-cho, Sakyo-ku, Kyoto University, Kyoto 606-8502, Japan

2 Warnell School of Forestry and Natural Resources, University of Georgia, 180 E. Green Street, Athens, GA 30602, USA

3 Department of Forest Engineering, Resources and Management, College of Forestry, Oregon State University, 280 Peavy Hall, Corvallis, OR 97331, USA 


\section{Introduction}

Optimisation can be described as the process(es) required for ensuring the best use of available resources either in the course of minimising or maximising an objective criteria [1], or in the course of minimising the amount of resources needed for achieving a given objective. In other words, optimisation is the process of selecting the best set of actions, or of making the best decisions, for a given problem or system with given priorities and prerogatives. Optimisation also facilitates the development of knowledge concerning the behaviour of the problem or system [2] in response to various constraints or objectives. Optimisation often requires that a problem be modelled using a system of constraints and that an objective or response function be created that shares decision variables with the constraints. Although some have suggested that optimisation of forest resources is gradually being replaced by other considerations in planning $[3,4 \cdot \bullet]$, and others have emphasised the need to acknowledge risk and uncertainty in planning and the challenges associated with these efforts [5], optimisation processes are still important for providing guidance in the allocation of work, the assignment of management actions, and the assessment of supply chains, and how these might be best managed spatially or temporally.

In forest planning, decision-making processes often use optimisation approaches for developing optimal harvest schedules that will best meet the objectives of the landowners or land managers. A common way of meeting landowner objectives is to maximise their perceived benefit. The net present value (NPV) of potential actions is one of most widely used metrics to quantify the perceived benefit of a landowner or land manager, and it often represents the decision makers' preference or goal in the optimisation system. The actual management decision environment is not that simple; however, as a number of operational limitations can restrict the set of possible actions chosen for incorporation into a plan of action. Besides economic values, ecological and sociological values of a person or organisation may guide the decision-making process and may make optimisation problems complicated and difficult to solve. Further, governmental laws and regulations can influence the decision-making process. In some cases, the objectives of a planning problem may involve spatial relationships, such as instances where key habitats or scheduled harvest areas need to be aggregated. This aspect of management can result in a non-linear optimisation problem, making it difficult to locate a mathematically optimal solution using exact methods (e.g. mixed integer programming) in a reasonable amount of time unless some of the relationships can be approximated linearly. Heuristic and simulation methods may therefore be employed to assist in the development of forest management plans. Exploring forest management alternatives with a simulation process has value yet only illustrates alternatives that landowners may have given transition probabilities and successional relationships. Well-designed heuristic models may be able to provide nearoptimal solutions to complex problems. However, since the optimal schedule of management activities is generally not located using these methods, they are not the focus of this review unless the associated published research suggested optimisation was achieved.

Proof of optimality is problematic and dependent on the type of objective and types of constraints that define a planning problem. For linear problems, the solution space forms a convex hull that only requires the extreme points be assessed to determine the optimal solution, as is performed using the linear programming simplex method. In general, for nonlinear problems, extrema can be located using first-order conditions, where the first derivative of the objective function is zero or undefined (critical points of a differentiable function). In a non-convex case, second-order conditions can then be used to determine whether the points in the solution space are locally optimal [6]; a matrix of second derivatives (Hessian Matrix) can be used for this purpose [7]. Although not applicable to every type of optimisation problem, KarshKuhn-Tucker conditions can be used to determine the necessary optimality conditions of problems with equality or inequality constraints. Other metrics such as the strong stationary condition and the Mordukhovich stationary condition can be used to identify the existence of local optima in mathematical problems with equilibrium constraints [8]. With respect to the optimal allocation of multiple resources, conditions can be found where it will become impossible to increase the production or availability of one desired outcome without harming the production or availability of another. When located, this measure of efficiency can be graphed as a Pareto frontier for a multi-objective planning model and can be used to visualise the production possibility frontier that illustrates the trade-off between competing goals.

The levels of planning within a forest management organisation are sometimes clear, and other times they may be clouded. In order to meet the needs of a forest landowner or land manager, a planning process may be combined into single system of analysis or more likely it may be disaggregated into hierarchical systems. The hierarchy may range from broad-scale concerns over long-term sustainability to finescale operational decisions necessary to accomplish daily, weekly, or monthly goals. Hierarchical planning therefore is often related to the timeframe and data required of the planning effort. Three general levels of forest planning are often recognised: strategic, tactical and operational. Strategic forest planning rests at the highest level in the hierarchy and generally focuses on long-term achievement of management goals. Strategic planning processes often include long-term forecasts of the economic, ecological and social outcomes of a determined set of actions. This type of planning can be performed annually or every $2-20$ years. The time interval often depends 
on the time available to complete the effort, the landowner's or land manager's ability to incorporate new data or knowledge into the planning process, the resources available for management planning, and the level of activity that has occurred on the forest or in the market place over a given period of time. Forest management plans for federal (public) land in the USA are developed once every 10 or 15 years, while for corporate entities, the time interval between the development of plans is much shorter. Strategic planning considers actions that may be implemented 40 to 100 years into the future. These plans may involve multiple rotations in the case of even-aged forests (and multiple entries into uneven-aged forests), yet they generally fail to recognise the exact location of proposed management actions (they are non-spatial solutions). Tactical forest planning is often performed annually or every 2 to 3 years. This type of planning process considers shorter time horizons (10-20 years) than strategic planning yet often recognises the proposed location of management actions that will be implemented to address larger purposes of the plan. At the lowest level in the hierarchy is operational forest planning, which is performed daily, weekly, monthly, or annually. With operational planning, the time horizon is very short, and very specific management features, such as logging crew sizes and trucking capacity, are considered. At this level, the technical details for implementing management actions are required.

One objective of this review is to describe recent advances in the use of optimisation in forestry, mainly from a forest management perspective, where activities are scheduled over time and across a forest. Although one can envision several different levels of optimisation in forest management, a second objective is to summarise the recent research by tree-level, stand-level, forest-level and landscape-level categories. Our work complements other recent reviews of methods, processes and approaches used in forest management and planning. For example, Rönnqvist [9] provided a valuable overview of the use of optimisation processes in forestry, from strategic and tactical planning of management practices to transportation systems, production planning and other operational concerns. An overview of the general use of optimisation in forestry and agriculture [10] illustrated some of the challenges facing the implementation and use of techniques for systems susceptible to economic and environmental risks and uncertainties. Methods for addressing multi-criteria decision-making processes and group decision making efforts have also been reviewed [11]. Other recent reviews include assessments of the value of participatory planning approaches in forest management $[3,5,12]$, the incorporation of risk and uncertainty into forest planning [5], the availability and characteristics of decision support systems for forest management purposes $[4 \bullet \cdot, 13,14]$ and the lessons learned from the development of these tools [15•], the use of knowledge management tools, approaches and methods [16-18] and other computerised tools [19] associated with forest management decision-making processes. Optimisation processes are often, in fact, key components of decision support systems [20].

Several recently published reviews are also of value to those interested in optimisation methods applied to forest management problems. For example, Diaz-Balteiro et al. [21] provide a review of the application of goal programming with respect to forest management and planning, and Bettinger et al. [22•] and Keenan [23] review the integration of climate change considerations into forest management and planning efforts. What follows is a more general review of the recent literature with respect to optimisation practices used in forestry.

\section{Materials and Methods}

We focused our assessment of recent advances in forest optimisation on peer-reviewed research papers that were published between 2010 and the development of this review in journals where information was provided primarily in English (with two exceptions). The focus of our review was on papers that described tree-level, stand-level, forest-level, or landscape-level optimisation approaches to forest management issues. In alphabetic order, we surveyed the following 30 forestry and natural resource management journals: Annals of Forest Science, Canadian Journal of Forest Research, Computers and Electronics in Agriculture, Croatian Journal of Forest Engineering, Ecological Modelling, European Journal of Forest Research, Folia Forestalia Polonica, Forest Ecology and Management, Forest Policy and Economics, Forest Research: Open Access, Forest Science, Forest Science and Technology, Forest Systems, Forestry, Forests, iForest, International Journal of Forest Engineering, Journal of Forest Research, Journal of Forestry, Mathematical and Computational Forestry and Natural-Resource Sciences, Natural Resource Modelling, New Zealand Journal of Forest Science, Open Forest Science Journal, Open Journal of Forestry, Scandinavian Journal of Forest Research, Schweizerische Zeitschrift für Forstwesen, Scientia Silvae Sinicae, Silva Fennica, South African Forestry Journal and Turkish Journal of Forestry and Agriculture. These journals include content that represent worldwide perspectives on advances in forest management. Although one or two journals that do not publish in English are included, other important journals (e.g. printed in Russian, German, Polish, French, Chinese and Japanese languages) were omitted from the review due to access issues and because they may have required extensive language translation that exceeded resources available for this review.

We examined the titles, abstracts and keywords of the potential forest optimisation papers within these journals and made an initial decision as to whether to include them in this assessment. If it was unclear from this information whether 
the content of a paper adhered to our standards, the methods section of a paper was reviewed to finalise the decision regarding inclusion in the review. We sought papers that demonstrated or described an optimisation approach or, alternatively, presented a case study that utilised an optimisation approach. Papers that suggested optimisation had been performed were not included in our review when an optimisation method was not evident. These included papers describing simulation approaches, those that mainly had a forest growth and yield emphasis, and those that involved an examination of replicated silvicultural treatments. One grey area involved the use of heuristic methods to optimise a system. If the authors of the related published research suggested that optimisation may have had occurred or an optimisation process had been followed, these works were included in our review.

From our collection of recent research (85 published papers), we recorded the journal title, publication date, optimisation method, optimisation level (tree, stand, forest, landscape), and the objectives and constraints associated with the planning problems. We summarised the results based on the optimisation methods employed and the types of objectives and constraints that were used. Any omissions on our part are either purely accidental or because the published research fell outside of the parameters (journal or time period) of the study.

\section{Results}

The review revealed that over half (52.9\%) of the published, peer-reviewed forest optimisation papers have concerned forest-level optimisation issues (i.e. generally one owner, more than one stand, not the entire landscape, spatial gaps evident due to the presence of other landowners or land uses) (Table 1). About $34 \%$ of the published work centred on the optimisation of stand-level management regimes, and about $13 \%$ centred on landscape-level optimisation issues (i.e. multiple owners, entire landscape, no spatial gaps created by other landowners or land uses). Most (55.3\%) of the published work arose from European countries, and of these papers, $55 \%$ arose from Nordic countries. From the literature we assessed, $23.5 \%$ also arose from North America, and $15.3 \%$ arose from Asia. Five journals provided $60 \%$ of the published work on this subject (Forest Policy and Economics (15.3 \%), Scandinavian Journal of Forest Research (14.1\%), European Journal of Forest Research (11.8 \%), Mathematical and Computational Forestry and Natural-Resource Sciences (10.6\%), Forest Science (8.2\%)). With regard to stand-level optimisation research, Forest Policy and Economics (27.6 \%) and the European Journal of Forest Research (17.2\%) contained the most content according to our search of the literature. The Scandinavian Journal of Forest Research (17.8\%), Mathematical and Computational Forestry and Natural-Resource Sciences (15.6 \%) and Canadian Journal of Forest Research (13.3\%) were the leading journals of content associated with forest-level optimisation. At the landscape-level, leading journals were Forest Ecology and Management (27.3 \%) and Ecological Modelling (18.2 \%).

\section{Tree-Level Optimisation}

Tree-level optimisation processes often involve decisions to cut or leave (or otherwise manipulate the character of) each tree, or decisions regarding how to buck or manufacture various types of logs from each tree bole. Thus, at the tree level, optimal decision-making processes might involve determining the point in time where the value growth percent of the tree equals the assumed alternative rate of return of the landowner or land manager. This assumes that the value growth rate of the tree was at some point during the merchantable life of the tree above the alternative rate of return [24]. The value growth rate concept suggests that the decision facing a person is solely economic and that the person would choose to place their money in investments that at least earns the assumed alternative rate of return. However, optimisation at the tree-level could conceivably be based on aesthetic or forest health concerns, such as to minimise the time required to reach a given size (height or diameter) that increases the probability of withstanding the effects of fire. Alternatively, optimisation may be based on a tree's ability to provide suitable habitat conditions for a given species, or based on the volume or value growth rate of the individual tree.

At the tree-level, one paper we located emphasised the maximisation of net revenue from the selection and bucking of individual trees scheduled for harvest. Here, an optimal bucking algorithm was applied to develop the solution to the problem [25]. Additional literature was observed where the species diversity structure of a residual stand was improved through the use of a heuristic technique that selected individual trees to harvest, yet optimality was not ensured [26]. Other research published on this topic was presented earlier than the time frame we assumed for this review. A Web of Science search using the three keywords tree-level, optimisation, and forestry will help one locate two or three other papers on the subject published in the early 2000s. When considering optimal bucking of trees, some published work from the late 1980s and early 1990s may also qualify as tree-level optimisation methods.

\section{Stand-Level Optimisation}

Stand-level optimisation often involves processes for developing the very best management plan of action for a stand of trees $[27 \bullet \bullet]$, not dependent directly on any forest or landscape goals. These processes can be applied to even-aged [28] or uneven-aged (continuous canopy) stands of trees. Within even-aged forests, all of the trees are very similar in age. 
Table 1 Objectives observed in peer-reviewed forestry literature published since 2010 in 30 forestry journals

\begin{tabular}{|c|c|c|c|c|}
\hline & \multicolumn{4}{|c|}{ Level of analysis } \\
\hline & Tree & Stand & Forest & Landscape \\
\hline Maximise bare land value $^{a}$ & & $\checkmark$ & $\checkmark$ & \\
\hline Maximise net present value ${ }^{b}$ & & $\checkmark$ & $\checkmark$ & $\checkmark$ \\
\hline Maximise other economic value & $\checkmark$ & $\checkmark$ & $\checkmark$ & $\checkmark$ \\
\hline Maximise wood production & & $\checkmark$ & $\checkmark$ & $\checkmark$ \\
\hline Maximise carbon stocks / sequestration & & $\checkmark$ & $\checkmark$ & \\
\hline Maximise even-flow/sustained yield & & $\checkmark$ & $\checkmark$ & \\
\hline Maximise utility ${ }^{\mathrm{c}}$ & & & $\checkmark$ & \\
\hline Maximise water yield & & & $\checkmark$ & \\
\hline Maximise non-timber forest products & & & $\checkmark$ & \\
\hline Maximise employment & & & & $\checkmark$ \\
\hline Maximise scenic beauty & & & & $\checkmark$ \\
\hline Maximise species saved & & & & $\checkmark$ \\
\hline Maximise fire safety & & & & $\checkmark$ \\
\hline Maximise older forest area / habitat & & & & $\checkmark$ \\
\hline Maximise tree structure / species diversity & & $\checkmark$ & & \\
\hline Maximise tree diameter distribution goal & & $\checkmark$ & & \\
\hline Minimise deviations in wood flow & & & & $\checkmark$ \\
\hline Minimise deviations in goals ${ }^{\mathrm{c}}$ & & & $\checkmark$ & \\
\hline Minimise logistical costs & & & $\checkmark$ & \\
\hline Minimise sediment produced & & & $\checkmark$ & \\
\hline Minimise perimeter of reserves & & & $\checkmark$ & \\
\hline Minimise deviations in age class goals & & & $\checkmark$ & \\
\hline Minimise harvest reduction ${ }^{\mathrm{d}}$ & & & $\checkmark$ & \\
\hline Minimise discounted expected damage & & & $\checkmark$ & \\
\hline Minimise risk & & & & $\checkmark$ \\
\hline \multicolumn{5}{|c|}{$\begin{array}{l}{ }^{a} \text { Discounted value over infinite rotations or very long periods of time; soil expectation value, land expectation } \\
\text { value }\end{array}$} \\
\hline \multicolumn{5}{|c|}{${ }^{\mathrm{b}}$ Discounted value over one rotation or relatively short periods of time ( $10-100$ years) } \\
\hline \multicolumn{5}{|l|}{${ }^{\mathrm{c}}$ With respect to a number of goals } \\
\hline${ }^{\mathrm{d}}$ Losses due to insect outbreaks & & & & \\
\hline
\end{tabular}

Within uneven-aged forests, there are two or more distinct age classes of trees. For either type of stand, the planning process can involve analysing a number of options for intermediate treatments, final harvest and site preparation decisions (in the case of even-aged forests) based on the initial condition of each stand and the desires and needs of a landowner or land manager. The main optimisation problems associated with stand-level optimisation are the rotation length problem (for even-aged stands), the thinning problem (for both types of stands) and the stand density management problem (for uneven-aged stands). The rotation length and thinning problems typically centre on economic and commodity production objectives, while the stand density management problem centres on a combination of commodity production and forest health objectives. Additionally, the stand density management problem reflects the fact that the attention of certain forest managers has shifted to concerns of biodiversity and forest health. While typically employed in uneven-aged forests in North America, stand density management can also refer to the management of even-aged stands and concerns of growth and vigor.

Of recent work (Table 2, [29-112]), a sizable portion involved stand-level optimisation methods (Fig. 1). With respect to stand-level optimisation methods, a wide range of objectives have been explored recently in the literature. The most frequently used objectives involved maximising either NPV of a single rotation (even-aged forests) or defined period of time (mainly uneven-aged forests), or maximising the bare land value of multiple rotations or long (perhaps infinite) periods of time. Most (62.1\%) of the stand-level optimisation work concerned issues in Europe, and most of these (61.1\%) involved forests in Nordic countries. A smaller amount of the published work (17.2\%) concerned stand-level forest optimisation issues in Asian countries (Iran, Turkey, Turkmenistan, 
Table 2 Summary of recent literature involving optimisation in forest management from peerreviewed forestry literature published since 2010 in 30 forestry journals

\begin{tabular}{lll}
\hline Level of optimisation & Process & Reference number \\
\hline \multirow{2}{*}{ Stand } & Heuristics & $29,30,31,32,33,34,35,36,37,42$ \\
& Non-linear programming & $38,39,40,41,43$ \\
& Faustmann optimisation & $44,45,46,57$ \\
& Hooke and Jeeves & $47,48,49$ \\
& Nelder and Mead & 34,50 \\
& Other & $51,52,53,54,55,56,57$ \\
Forest & Mixed integer programming & $58,59,60,61,62,63,64,65,66,67$, \\
& & $68,69,70,71,72,73,74,75,76,77$ \\
& Linear programming & $61,62,63,64,78,79,80,81,82,83$, \\
& Goal programming & $84,85,86,87,88$ \\
& Heuristics & $63,78,89,90,91,92,93,94$ \\
& Non-linear programming & $66,77,88,95,96,97,98$ \\
& Other & 79,99 \\
& Linear programming & $92,100,101$ \\
Landscape & Mixed integer programming & $102,103,104,105,106,107,108$ \\
& Heuristics & 109,110 \\
& Goal programming & 111,112 \\
\hline
\end{tabular}

Vietnam, China), and $13.8 \%$ of the published papers concerned stand-level forest optimisation issues in North America. The types of optimisation methods utilised in stand-level optimisation papers were quite diverse and led by heuristics (34.5\%) and non-linear programming (17.2\%; Table 2). These and other breakdowns of the methods employed are not clean, as any one single paper may have described multiple methods for optimising forest systems.
Other optimisation methods included complete enumeration, Faustmann optimisation, the Hooke and Jeeves method, dynamic programming, the control method, Markov decision processes, the Nelder and Mead method, Valsta's scenario technique and the Escalator Boxcar Train method. In addition, one paper utilised the biological rotation age (maximisation of mean annual increment) as an optimisation metric attained through inspection of the growth dynamics of a stand. This
Fig. 1 Distribution of source of recent literature and type of problem addressed

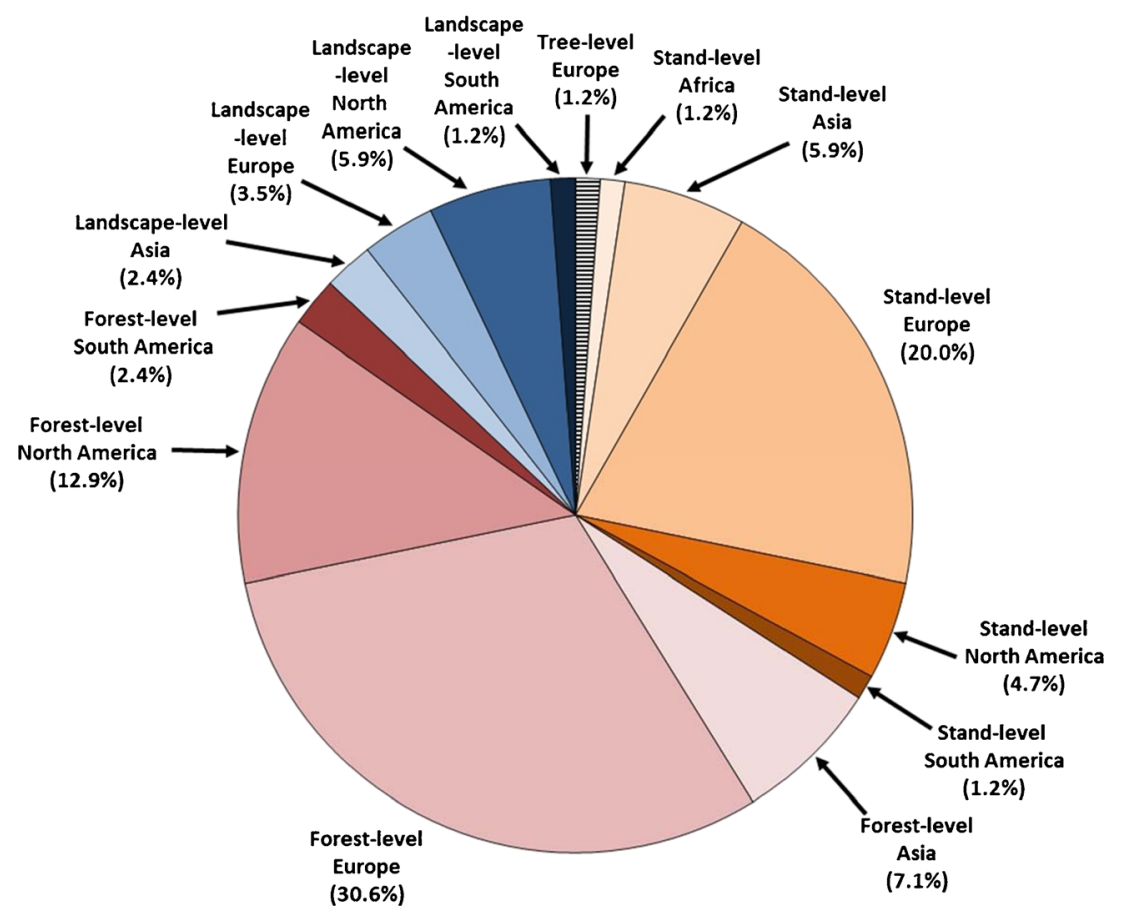


metric is often considered to be the biological rotation age for even-aged stands when wood production is the objective, and is often specified in forest plans designed for US national forests (e.g. [113]) or state forests (e.g. [114]). The use of heuristics is interesting, since our review tended to avoid methods that could not guarantee optimality of a system. However, they are included here because the authors suggested that a system was optimised by using the heuristic processes. This grey area extends to mathematical processes that should guarantee optimality, yet due to assumptions made in the search processes (i.e. optimality tolerances), these too may not guarantee optimality of a system. The constraints at the stand-level mainly included operational concerns such as the timing of entries for intermediate treatments or partial harvests, limits on amounts removed during partial harvests, maintenance of diameter distributions, requirements for minimum harvest volume prior to the scheduling of a harvest treatment, and requirements for minimum residual tree densities and species compositions. However, a few constraints related to impacts as a result of climate change and wildlife habitat.

With regard to methods used for stand-level optimisation, the Faustmann optimisation process has long been used as a way to optimise the management of a stand of trees, and involves an assessment of the economically optimal course of action by maximising net stand value, taking into account current and future conditions of forests on a piece of land. One common stand-level decision involves taking action (harvest) when the value growth of the stand is less than or equal to the opportunity cost of not taking action. This decision process unifies the concepts of optimisation and forest valuation and advances the idea that management performance is measured by the gain in equity of the investment as a result of management actions [115]. The process requires one to model or monitor the change in standing volume of a stand of trees while modelling alternatives, and to determine which structural conditions of a stand ensure the greatest volume growth [55].

Markov decision methods involve state-transition matrices that represent the probability of movement from one state to another at different stages of the optimisation process. Markov decision process models can be solved using a Faustmann optimisation process associated with linear or dynamic programming methods. In Zhou and Buongiorno [37], Douglasfir (Pseudotsuga menziesii) and western hemlock (Tsuga heterophylla) stand-level growth was simulated using probabilities of movement from one state to another over the course of 1 year. Prices were modelled on an annual basis using a Markov chain, and discount (interest) rates varied based on transition probabilities. The NPV of the management regimes were then optimised taking into account the state of the stand and the potential variability in prices and interest rates.

Dynamic programming involves describing a problem as a set of stages (time periods) and states (conditions within the time periods). Introduced to forestry in the 1960s [116, 117], during the 1970s and 1980s, this was perhaps the most prevalent method studied for stand-level forest management decisions that involve determining the optimum growing stock or rotation age of even-aged forests. Paths between initial stand conditions and final stand conditions are represented as a network described by reasonable definitions of stand states (e.g. residual basal area levels) and reasonable management actions that might be employed. The Pontryagin minimum principle is used to ensure that the necessary conditions for an optimal management regime have been located after examination of the various paths within the network. In Ferreira et al. [56], dynamic programming was used to assess the management options for short-rotation coppice stands of Eucalyptus globulus in Portugal while taking into account the risk of loss due to wildfire. Probabilities of complete and partial damage from wildfire and their effects on regeneration are factored into the states and transitions as bare land value is optimised.

The Hooke and Jeeves method and the Nelder and Mead method for solving stand-level optimisation problems are types of pattern search processes that reduce the solution space and attempt to converge upon an optimal solution. Technically, both may be considered heuristic methods although the Nelder and Mead process does employ concepts related to the Simplex Method. de-Miguel et al. [47] used the Hooke and Jeeves method to optimise bare land value for Turkish pine (Pinus brutia) stands in Turkey that were capable of producing honey (from bees, using pine pollen) in addition to timber values. Möykkynen and Pukkala [49] also used the Hooke and Jeeves method to optimise bare land value, but for Scots pine (Pinus sylvestris) and Norway spruce (Picea abies) stands that faced root rot problems caused by previous stands. Pukkala [48] described the use of the Hooke and Jeeves algorithm for locating optimal management regimes for mixed (pine, spruce and birch) stands in Finland when optimising bare land value that included prices for sequestered carbon. Pukkala et al. [34] used the Nelder and Mead method to develop optimal stand-level management regimes for both evenaged and uneven-aged pine and spruce stands in Finland when the bare land value was optimised. Finally, Pukkala and Kellomäki [50] described the use of the Nelder and Mead method to develop optimal stand-level management regimes for even-aged mixed species (Scots pine, Norway spruce, silver birch (Betula pendula) and white birch (Betula pubescens)) stands in Finland when the bare land value was optimised in light of stochastic prices and climate-related changes in tree growth.

Heuristic methods employ logic and rules to guide the search for near-optimal results. Each have processes for releasing the search process from local optima and for both diversifying the search through less-explored areas of the solution space, and for intensifying the search around highquality solutions. Ideally, well-designed heuristic methods 
would be able locate the global optimal solution to a problem; however, there are no tests of optimality to ensure this result. Further, when stochastic processes are employed in a heuristic search, one might locate a different solution with each independent run of these models, which suggests that multiple attempts for solving a problem may be necessary to provide assurance that the best result of these is near-optimal. The heuristic methods that were explored included genetic algorithms and simulated annealing. A genetic algorithm is a population-based heuristic ( $p$-metaheuristic) that maintains a set (population) of feasible solutions (forest plans), selects a subset from the population (parents) to break apart and recombine (into children) with the goal of creating better solutions. A stochastic process (mutation) is used to prevent the population from converging upon local optima. For stand-level management problems, a genetic algorithm would maintain several different feasible solutions to the problem in the memory of the computer and use these to create new feasible solutions to a problem through re-combination and stochastic adjustment. Genetic algorithms have been developed recently [29-31] to optimise economic concerns at the stand level. Similar $p$ metaheuristics were recently demonstrated for maximisation of wood production [34] and forest structure [35] at the standlevel. Constraints in most of these models were of the operational type (e.g. planting density and cutting cycle interval). Simulated annealing is a point-based heuristic ( $s$ metaheuristic) that adjusts the condition of one feasible solution (management regime in this case) through stochastic rescheduling of activities, with the goal of refining the solution by only allowing changes that increase (or decrease with a diminishing probability) the value of the solution. At the stand level, this would involve randomly changing the sequence of events (management actions) or the timing of events applied to a piece of land, hoping to improve the value of the objective for the land. At the onset of the search, this diversifies the search process to avoid becoming mired in local optima. However, with each new randomly chosen event, the probability of accepting an inferior action (with respect to the change in the objective) into the solution declines, forcing the search process to intensify the search around highquality local optima. Eriksson et al. [33] described the use of simulated annealing to select the near-optimal timing of intermediate treatments and residual tree density levels within a stand given a fixed final felling age.

Valsta [118] presented a technique for stand-level optimisation problems with stochastic elements by developing a set of scenarios where each is associated with a probability of occurring over the time horizon. The scenarios are used in lieu of random processes, and optimisation is approximated through deterministic non-linear methods. In Pukkala and Kellomäki [50], the scenario technique was employed to evaluate the optimal management regimes for even-aged mixed species stands in Finland when the product prices and the growth of trees were modelled using stochastic processes. An assumption regarding a change in the climate, and its influence on the relative growth of the trees was also incorporated into the model. The process was used to optimise the NPV of the management of the forest and subsequently determine the optimal rotation length and thinning regimes.

The Escalator Boxcar Train method involves formulating the objective function of a problem in such a way as to maximise a system subject to a set of ordinary differential equations and subsequently solve the problem with commonly available mathematical programming software. In Goetz et al. [54], the discounted net benefits of timber production and carbon sequestration were optimised for a Scots pine stand to determine the effects that changes in carbon prices might have on the optimal management regime. To locate the optimal solution to the problem, integral-partial differential equations describing the management situation were transformed into a closed system of ordinary differential equations that approximate the problem, which is subsequently solved using standard mathematical programming methods.

\section{Forest-Level Optimisation}

Due to the fact that a broader perspective is often considered in forest management, forest-level and landscape-level planning processes are often employed. For our purposes, forest-level optimisation involves a collection of stands, not necessarily contiguous, under the management of one landowner or land manager. Many of the issues facing forest-level management planning today are spatial in nature. These include the placement of activities across the landscape with regard to other recent (or planned) activities, the location of significant features (e.g., older forest habitat), and the maintenance of these over time. While our review does not focus on road management issues per se, the availability of access to parts of the forest, and the maintenance of access routes are also spatial issues; they are often linked to planned harvest activities. Resource and management activity allocation over time is perhaps the larger issue for forest optimisation. A forestlevel management problem can utilise a time horizon that ranges from 1 year to over 100 years, and time intervals (or periods) that range in size from quarters (3 months) to decades. Ensuring an adequate wood flow over time is a common issue for forest- and landscape-level optimisation problems, as are green-up periods in association with harvest adjacency issues associated with regulations [119] or certification program policies [120].

The optimisation methods recently described that concentrated on forest-level management issues included an even wider range of objectives than those employed at the stand level (Table 2). The main objectives seemed to involve the maximisation of NPV of a defined period of time, maximisation of other economic values and maximisation of 
scheduled wood volume. Here, the other economic objectives included the value of the ending inventory, the net income and the discounted net revenue. At the forest level, mixed integer programming $(48.9 \%)$ and linear programming $(33.3 \%)$ were the main methods employed, followed by goal programming $(17.8 \%)$ and heuristics $(15.6 \%)$. Other optimisation methods included binary search, non-linear programming, bin packing, portfolio theory, dynamic optimisation, compromise programming and real options theory methods. Of the forest-level work, most (57.8 \%) again arose from European countries and were nearly equally split between Nordic countries and countries of continental Europe. A smaller portion of the peer review literature regarding forest-level optimisation concerned forest optimisation issues in North America (24.4\%), Asia (13.3 \%) and South America (4.4\%). The constraints used at the forest level involved area control, wood flow (minimum, maximum, periodic fluctuation, even-flow, etc.), harvest area (opening) sizes, adjacency of harvests, sizes of core (older forest) areas, minimum harvest ages, ending standing inventory levels and others that relate to maintaining biodiversity or wildlife habitat, producing non-timber forest products, and providing recreational experiences.

At the forest level, the optimisation of NPV (for example) within a linear programming environment might involve using the following general problem formulation:

$\operatorname{Max} \sum_{t=1}^{T}\left(\left(\sum_{z=1}^{Z} \sum_{p=1}^{P}\left(x_{z t} R_{z p t}\right)-\sum_{z=1}^{Z}\left(x_{z t} C_{z t}\right)\right) /(1+d)^{t}\right)$

subject to

$$
\begin{aligned}
& \sum_{z=1}^{Z} \sum_{p=1}^{P}\left(x_{z t} v_{z p t}\right)=V_{p t} \forall t \\
& V_{p t} \leq\left(G_{p t}+\delta_{p t}\right) \\
& V_{p t} \geq\left(G_{p t}-\delta_{p t}\right)
\end{aligned}
$$

Within the objective function, stand-level costs $\left(C_{z t}\right)$ associated with managing each stand $(z)$ during each time period $(t)$ are subtracted from the revenues $\left(R_{z p t}\right)$ with generating products $(p)$, and the net is discounted to the present using an assumed discount rate $(d)$. The $x_{z t}$ decision variables are continuous real numbers for stand $z$ during time period $t$ in linear programming models. They often represent the percent of a stand that is managed in a certain way during the time period in question. These decision variables are often given binary values representing harvest (1) or no-harvest (0) decisions in mixed integer programming models. Volumes for each product generated by each stand $\left(v_{z p t}\right)$ might be accumulated and maintained within bounds $\left(G_{p t}+\delta_{p t}, G_{p t}-\delta_{p t}\right)$ to represent wood flow constraints. As examples of recent work in this area, Korosuo et al. [62] developed a linear programming model to maximise the net present value of management activities while addressing wood flow, conservation, recreation and water-related constraints. Baskent et al. [88] developed a linear programming model to maximise wood production subject to area control and even-flow of wood volume constraints. And, Hennigar et al. [81] developed a linear programming model to minimise harvest reductions due to losses from an insect infestation while imposing a wood flow constraint. Other examples of forest-level linear programming models (see Table 2) generally include an economic or commodity production objective and constraints associated with wood flow, conservation or sustainability.

Goal programming formulations are similar to linear programming models except that the objective consists of minimising weighted deviations from some target goals (economic, timber, wildlife habitat, etc.):

$\operatorname{Min} \sum_{i=1}^{k} \sum_{t=1}^{T} w_{i t} d_{i t}^{+}+w_{i t} d_{i t}^{-}$

subject to

$f_{i t}(u)-d_{i t}^{+}+d_{i t}^{-}=G_{i t}$

$d_{i t}^{+}, d_{i t}^{-} \geq 0$

$u \in F$ ( $F$ is afeasible set)

In a goal programming problem formulation, $d_{i t}{ }^{+}$and $d_{i t}{ }^{-}$ are positive and negative deviations from goal $i$ during time period $t$. Often, each goal is accompanied by a user-defined weight $\left(w_{i t}\right)$ that reflects the importance of each goal. A function $\left(f_{i t}(u)\right)$ is developed to assess each goal (e.g. wood flow and carbon sequestered), and the deviations are determined by comparing the outcomes to the desired goal level $\left(G_{i t}\right)$. Recent work regarding the use of goal programming in forest-level management has been quite creative. For example, Chen et al. [92] used goal programming to minimise deviations from target values associated with timber harvests, recreation opportunities, hunting experiences and wildlife habitat goals. Maroto et al. [89] used goal programming to minimise deviations from target values associated with biodiversity interests, climate change mitigation activities and erosion control measures. Aldea et al. [90] attempted to minimise deviations from economic, carbon sequestration, harvest volume and mushroom production goals.

Mixed integer programming is similar to linear programming except that some of the decision variables are limited to integer values. The branch and bound and the cutting plane algorithms (or a combination of the two, branch and cut) are commonly used to address these problems. A branch and bound algorithm involves a systematic search of potential solutions that are represented by a tree-like structure where each 
decision within a hierarchy is assigned one of its feasible integer choices. The continuation of the search through the various branches is either allowed or disallowed based on the resulting feasibility and the estimated bounds on the optimal solution of other solutions on the branch. The cutting plane algorithm divides the feasible region of the solution space through the examination of linear inequalities. Through this process, an optimal integer solution is identified by introducing new slack variables and constraints into the relaxed linear problem (the basic feasible solution). As examples of recent work in this area, Tóth et al. [73] recently developed a mixed integer programming model to maximise the discounted net revenue and forest value at the end of the time horizon while addressing adjacency constraints, minimum harvest ages and wood flow constraints. Similarly, much of the recent work describing the application of mixed integer programming to forest-level problems involved maximisation of an economic goal [e.g. 58, 70, 71, 73-75 and others]. The need to control the timing and location of adjacent harvests likely prompted the choice of this method over others previously mentioned.

The heuristics described recently to optimise forest-level management problems included genetic algorithms and simulated annealing, which were mentioned earlier, and tabu search. In one example of recent work regarding the use of heuristic methods for optimising forest-level management plans, Fotakis et al. [97] developed a genetic algorithm to maximise commodity production outcomes while minimising sediment production, subject to wood flow constraints. Borges et al. [77] developed a simulated annealing algorithm to maximise net present value subject to harvest adjacency and wood flow constraints. Kangas et al. [98] also developed a simulated annealing algorithm, but to maximise the utility of a forest plan, where utility was defined to include economic, commodity production, forest fragmentation and patch size interests. Kangas et al. [66] developed a tabu search algorithm to minimise deviations from 36 commodity production goals subject to constraints related to the area of, and volume generated from, broadleaved stands, and the retention of older forest areas.

Binary search is essentially a simulation method that makes progressively better guesses at the optimal solution by narrowing the range of potential solution values. Mainly, this method is used in conjunction with a wood flow objective such as the maximisation of an even-flow of scheduled timber harvest volume. As employed in forest planning, the method is iterative and used to schedule management activities (typically harvests) one period at a time using simple decision rules. For example, if a target harvest volume was identified, binary search would schedule first-period harvests from available stands using a rule (e.g. oldest stand first) until a sufficient scheduled volume matched or exceeded the target volume. Then, binary search would perform a similar process for the second period, and so on, until either all periods were attended to, or no more stands were available for harvest. A decision would then be made either to (a) increase the target and schedule the harvests again, (b) decrease the target and schedule the harvests again or (c) stop the process and report the best schedule of harvests that were feasible with respect to highest target volume. This type of forest-level planning process is similar to bin packing algorithms that attempt to schedule activities (harvests, for example) to best match the desired outcomes (harvest levels, for example). In the lone forest planning paper that described a bin packing algorithm [64], it was shown that for normal or regulated even-aged forests that have a volume maximisation objective, each stand should be scheduled for final harvest at the stand-level optimal solution that maximised mean annual increment.

Dynamic optimisation is similar to Markov decision methods in that states and transition matrices are used to represent the probabilities of events occurring, yet in these cases, the transition probabilities of multiple stands from within a forest being treated or affected (harvested or burned, for example) are modelled rather than the specific transitions in growth rates of stands as a result of different thinning regimes or planting densities. Konoshima et al. [96] used dynamic optimisation for a forest-level problem that maximised net revenue and terminal forest value while developing a spatial pattern for management activities that would reduce fire risk. This process required the development of weather and fire ignition probabilities, and the modelling of the spread of fires.

For reducing the amount of risk and increasing the yields associated with financial assets, portfolio theory has been suggested as a method for determining the optimal combination of investments. Portfolio theory was used in Neuner et al. [100] to demonstrate the optimisation of NPV for the selection of tree species to regenerate in stands across a forest given the expenses involved, the potential risk of loss and the potential growth of each stand. Monte Carlo simulation was employed to develop a frequency distribution of outcomes given the stochastic elements involved. The optimal portfolios of stands were those that achieved the rate of return desired given a budget constraint.

Compromise programming is similar to goal programming in that the process attempts to locate solutions with outcomes that are similar to the desired outcomes of a forest plan. For multiobjective problems, most efficient and most balanced compromise solutions are developed to understand the limits within which the management possibilities exist. Aldea et al. [87] used compromise programming to maximise the value of timber and mushroom production in a Scots pine forest in Spain.

Real options theory methods can be designed for forest optimisation problems to allow an analyst to acknowledge an option value related to uncertainty and the possibilities of disturbance. In cases such as these, an analysis would involve assessing the timing of decisions (management actions) in 
order to take advantage of changing circumstances. Sims [101] described the use of real options theory when applied to a forest-level planning problem that involved the salvage value of timber killed as a result of an insect infestation. The option value was the opportunity cost of harvesting the damaged timber immediately rather than waiting for additional information concerning the infestation. Delaying the salvage harvest operation resulted in reduced timber and non-timber values; thus, the optimisation was designed to minimise expected losses and to determine the optimal time to salvage the dead timber (if removed at all).

\section{Landscape-Level Optimisation}

Our perspective on landscape-level optimisation involves multiple landowners and contiguous (entire) watersheds, political units (e.g. counties and provinces) or landscapes. Optimal stand-level decisions may not be appropriate when forest- or landscape-level goals, such as wood flow or harvest timing and location issues, are important. The recently published landscape-level optimisation methods we located included a smaller, yet broader (and perhaps similar) set of ideas that were employed at the forest level. The main objectives seemed to be the maximisation of wood volume produced, the maximisation of NPV, the maximisation of other economic values and the minimisation of deviations in scheduled wood volume. The other economic values included net income, equivalent annuity, and the value of fuelwood. At the landscape level, linear programming was the most prevalent method presented in these articles $(63.6 \%)$, followed by mixed integer programming $(18.2 \%)$, heuristics $(18.2 \%)$ and goal programming $(9.1 \%)$. Again, a single article may have contained a description or the use of more than one method. Forty-five percent of the published work at this scale concerned landscape optimisation issues in North America (exclusively Canada), and $27 \%$ concerned landscape optimisation issues in Europe. A small portion of the published literature concerned landscape optimisation issues in Asia (18\%) and South America (9\%). Similar to the recent forest-level literature, the constraints used at the landscape-level involved those related to area harvested, wood flow (regulation, nondeclining yields), minimum harvest ages, ending standing inventory levels and development or maintenance of wildlife habitat.

As examples of recent work involving landscape-level optimisation, Colombo et al. [104] developed a linear programming model to maximise commodity production subject to constraints associated with forest reserves and limits on area and volume harvested. Savage et al. [106] also use linear programming to maximise a commodity production objective, also subject to forest reserves yet with the interjection of stochastic fire losses. Hossain and Robak [105] developed a goal programming model for a landscape-level problem that minimised deviations from goals (developed through linear programming problems) related to commodity production, older forest structure and scenic beauty. Other work in this area (see Table 2) was also quite creative and diverse for landscape-level issues; included in a few were the recognition of broad-scale ecological indicators [109], species conservation concerns [110] and fire safety [111].

\section{Discussion}

As we have used it throughout this review, optimisation represents the process of selecting the best value (according to certain criteria) from a set of all available alternatives, and thus locating the best available solution given an objective function given its domain (or a set of constraints). Depending on the objectives and constraints of a plan, the optimisation of management can result in less waste (time and resources), lower management costs and improved ecological and social outcomes. These ideas are closely related to concepts of sustainability, a theme that has captured society's attention of late. While some systems may be impossible to optimise with mathematical methods (e.g. mixed integer programming) given the complexity of modern problems (number of decision variables, number of constraints), when alternatives (e.g. simulation models and heuristic models) are proposed, they come with one drawback - there is no guarantee of optimality. However, whether an optimal or near-optimal solution to a problem has been located, the solution represents a plan of action. Therefore, optimisation of a well-described system can produce a desirable plan of action, which then serves as a reasonable guide to the management of resources.

More commonly today, multi-objective optimisation is being pursued (a) as advances in technology and science provide the platform and opportunity upon which a model might be developed, and (b) as societal interests in the management of the natural environment evolve. This also suggests that relationships between decisions and outcomes should be quantifiable, although advances are being made in areas where human preferences (where not already evident in market prices) are important in the decisions being made. However, when pursued, multi-objective optimisation is difficult in many respects, particularly when the relationships between decisions and outcomes are non-linear or when the decisions are binary (or simply integer). In practice, without a mathematical model, it is likely that forest management organisations are simply selecting feasible solutions that do not violate major constraints. Unfortunately, some mathematical optimisation processes are not well suited for multi-objective forest planning problems, particularly when complex functional relationships between management actions or tree growth are unknown or estimated based on limited science. 
At all levels of forest optimisation, time is an influential issue due to the length of the planning horizon. The discounting of costs and revenues was often performed to reflect the notion that financial value changes over time. The discount rate assumed in a planning process can therefore significantly change the outcomes of an optimised plan. One may find that the stand-level optimal regime (timing of management activities) can change considerably as the discount rate is varied. These effects are more closely related to treelevel and stand-level optimisation issues, as the site index of a stand of trees, the assumed (or measured) density of each stand and how each stand is managed all affect economic returns. At other scales, a limited set of stand-level decisions are typically available in addressing forest-level or landscapelevel goals.

Although forestry has a long use of optimisation techniques, it is still an area where innovation is occurring in applying new methods to solve these problems. The forestry profession has a rich tradition of applying new approaches to solve interesting and complex management problems. What have remained consistent are the collections of objectives of optimisation processes to assist in the regulation of the forests. This continued use of classical methods is consistent with many of the examples of forest plans of North America that are presented in Siry et al. [121]. Further, the use of linear programming as the main management tool for optimisation is not surprising since we focused on optimisation methods (rather than simulation or heuristic methods). At least at the forest-level, this is consistent with the findings of a decade ago for North America [122].

Future research will in part likely have the goal of integrating both commodity outcomes (e.g. those marketed, such as wood production) and non-commodity outcomes (e.g. those not currently marketed, but important to society or land managers) into the larger optimisation system. Examples may include how harvests impact both water quality and water yield. Other optimisation systems may further explore methods to acknowledge ecological concepts that may be difficult to quantify, such as ecological health or resiliency, and how these can be integrated into optimisation methods. This has long been a recognised problem in natural resources management, as the necessary information is rarely available. However, science continues to evolve and realistic approaches to acquiring such information may eventually be developed. The close integration of optimisation processes and functional relationships among resources and outcomes can facilitate the exploration of larger areas of the decision space, as opposed to the use of simulation models for examining options. When it seems necessary for a planner to examine the trade-offs among conflicting objectives, a scenario analysis process can be of value [59]. Here, the optimal scenario will in part be defined by the subjective preferences of the decision-maker. Optimisation processes that facilitate the incorporation of preferences, through weights or penalties, and that provide feedback in a timely manner may be of great value to operational forestry decisions. Mixing optimisation methods has promise, as suggested in the review provided by Myllyviita et al. [123]. This can facilitate the integration of multiple tools, both quantitative and qualitative, and advance the application of optimisation to tactical and operational planning problems to arrive at higher quality solutions. We believe that as the problems shift from the well-quantified to the more qualitative, or where they must include the assorted values from large groups of people commonly found in collaborative decisionmaking efforts, this mixed approach will become more important in the future.

As the forest sciences and technologies continue to advance, future research will in part likely have the goal of increasing the number of opportunities for linking optimisation processes with information technology, primarily for tree-level decisionmaking processes. In the future, operational planning could use computer technology situated on (or within) forest machines as the platform for inventory control and dynamic optimisation of decisions. With advances in laser scanning, it is not unreasonable to imagine that someday individual tree decisions and movements of machines may be optimised with respect to economic (commodity production, cost control) or ecological (forest diversity, fire risk minimisation) concerns. Each potential action of a machine can thus be optimised by performing tasks such as optimal bucking of logs and benefit/costs analyses of tree harvest decisions.

Sustainability is a core concept for forest management organisations today and may involve a multi-criteria perspective on the management of land. Measures of sustainability vary, and management philosophies range from sustainable timber supplies to sustainable multiple-uses and sustainable ecosystems [124]. Prior reviews [e.g. 11] suggested that progress in these areas continue to be made. Based on the variety of research reviewed, particularly at the forest and landscape levels, it seems that these needs continue to be addressed. However, continued efforts to explore measurement and integration of sustainability into forest plans are necessary as society places demands on forest management organisations to demonstrate that the actions prescribed result in sustainable systems.

One could argue that a multi-criteria perspective has long been considered in forest planning. With respect to applications of optimisation processes towards forest plans, in the review provided by Diaz-Balteiro et al. [11], it was suggested that continued progress using a multi-criteria perspective on planning would be a fruitful and beneficial path for future research. Our review has shown that multi-criteria objectives continue to be explored in creative ways. Incorporation of carbon sequestration goals in response to global climate change has likely prompted some of these advances. However, concerns about biodiversity, sustainability and 
conservation continue to influence the adaptation of wildlife habitat, aquatic system and forest function models into the mathematical formulations of forest planning models. These types of efforts require functional response models that link the timing and placement of activities, along with changes in forest structure, to changes in outcomes of interest. While geographical logic can be used to accommodate these linkages, more often the functional response models require a direct quantitative relationship to management activities and changes in forests. As was noted in [10], continued efforts in these researchable areas are necessary as the values and needs of society change.

From our review, a few of the recently published articles address concepts and methods associated with risk and uncertainty, and a few address the wood supply chain. It was noted nearly a decade ago [10] that these were viable research areas. The risk of natural disasters (for example, fire) affecting resources continues to prompt research in this area $[60,96,106]$. Given the stochastic nature of many events that could affect forest resources, this still seems like a fruitful area for further research. As for the wood supply chain, our impression of whether recently published articles are addressing this concern is limited. This may be due to the constraints we placed on the review process. For example, articles describing the entire supply chain (tree to manufactured product) could be published in journals outside the scope of our list. Further, we limited our search to a landscape scale or smaller dimension. As a result, we omitted articles that expressed a primarily transportation or manufacturing perspective. However, issues associated with transportation systems [85] and mill harvest quotas [95] were acknowledged in our review.

\section{Conclusions}

Optimisation is the process of selecting the best set of actions or of making the best decisions for a given problem or system. Optimisation processes are employed in forestry in order to understand the best course of action for the scale of land recognised, given limited resources. In our case, it can involve (a) determining whether to harvest a tree or let it continue to grow, (b) identifying the best stand-level treatments to implement over time, (c) selecting the timing and placement of management activities within a forest or (d) assessing landscape-level productive capacity, social considerations, and environmental outcomes. Optimisation of a system is relative only to the objectives and constraints that are recognised in the problem being solved. In nearly every case, the objectives and constraints need to be quantified through functional relationships that link actions to the growth of trees (or stands) and the associated reactions of systems (economic, social, environmental) to the management of these resources. The outcomes of optimisation efforts (i.e. plans of action) should be viewed as either guides to the management of trees and forests, or sources of information that will be used in assessing alternative management scenarios. The forestry sciences continue to explore and evaluate approaches to the optimisation of systems using mature and novel operations research methods. In our examination of recent developments, we concentrated on tree-, stand-, forest- and landscape-level optimisation issues and noted that most of the recent published research on stand- and forest-level optimisation has concerned forests in Europe, specifically Nordic countries. At the stand level, optimisation seems to have drifted away from dynamic programming, once popular two or three decades ago, to a variety of methods that include heuristics and non-linear programming. Maximisation of an economic objective seems to be the most frequently employed strategy. At the forest-level, exact methods for optimising systems continue to be explored for their usefulness in addressing contemporary forest planning issues. Mixed integer and linear programming methods are still widely used, but advances have been made in the incorporation of complex issues into the forest-level problem. Landscape-level optimisation is a relatively new area of research and most often performed in areas where the resulting plan of action has an influence on the activities of all involved. Therefore, the development of these processes has been driven by the management of public land (Crown lands and licenses) in Canada rather than the heterogeneous ownerships (mainly privately owned lands) that is typical in parts of the USA or northern Europe.

Acknowledgments This work was supported by McIntire-Stennis project number GEOZ-0168-MS through the Warnell School of Forestry and Natural Resources at the University of Georgia.

\section{Compliance with Ethical Standards}

Conflict of Interests Mr. Kaya, Dr. Bettinger, Dr. Boston, Mr. Akbulut, Ms. Ucar, Dr. Siry, Ms. Merry and Dr. Cieszewski all state that they have no conflicts of interest to declare.

Human and Animal Rights and Informed Consent The article contains no studies with human or animal subjects performed by the authors.

\section{References}

Papers of particular interest, published recently, have been highlighted as:

- Of importance

•• Of great importance

1. Verhulst M. Joint optimization of long-range planning and shortrange programming. Oper Res. 1958;6(4):58-590.

2. Geoffrion AM. The purpose of mathematical programming is insight, not numbers. Interfaces. 1976;7:81-92. 
3. Menzel S, Nordström E-M, Buchecker M, Marques A, Saarikoski $\mathrm{H}$, Kangas A. Decision support systems in forest management: Requirements from a participatory planning perspective. Eur J For Res. 2012;131(5):1367-79.

4.• Vacik H, Lexer MJ. Past, current and future drivers for the development of decision support systems in forest management. Scand J For Res. 2014;29(Supplement 1):2-19. This paper presented a historical review of the development of decision support systems in forestry, along with the motivations and objectives that guided the development and use of the systems.

5. Pasalodos-Tato M, Mäkinen A, Garcia-Gonzalo J, Borges JG, Lämås T, Eriksson LO. Assessing uncertainty and risk in forest planning and decision support systems: Review of classical methods and introduction of innovative approaches. For Syst. 2013;22(2):282-303.

6. Burai P. Local-global minimum property in unconstrained minimization problems. J Optim Theory Appl. 2014;162:34-46.

7. Agnew D. Efficient use of the Hessian Matrix for circuit optimization. IEEE Trans Circuits Syst. 1978;25(8):600-8.

8. Ye JJ, Zhang J. Enhanced Karush-Kuhn-Tucker conditions for mathematical programs with equilibrium constraints. J Optim Theory Appl. 2014;163:777-94.

9. Rönnqvist M. Optimization in forestry. Math Program Series B. 2003;97:267-84.

10. Weintraub A, Romero C. Operations research models and the management of agricultural and forestry resources: A review and comparison. Interfaces. 2006;36:446-57.

11. Diaz-Balteiro L, Romero C. Making forestry decisions with multiple criteria: A review and an assessment. For Ecol Manag. 2008; 3222-3241.

12. Marques AF, Borges JG, Garcia-Gonzalo J, Lucas B, Melo I. A participatory approach to design a toolbox to support forest management planning at regional level. For Syst. 2013;22(2):340-58.

13. Packalen T, Marques AF, Rasinmäki J, Rosset C, Mounir F, Rodriguez LCE, et al. A brief overview of forest management decision support systems (FMDSS) listed in the FORSYS wiki. For Syst. 2013;22(2):263-9.

14. Valls-Donderis P, Ray D, Peace A, Stewart A, Lawrence A, Galiana F. Participatory development of decision support systems: Which features of the process lead to improved uptake and better outcomes? Scand J For Res. 2014;29(Supplement 1):71-83.

15. Marques AF, Ficko A, Kangas A, Rosset C, Ferreti F, Rasinmaki J, et al. Empirical guidelines for forest management decision support systems based on the past experiences of the expert's community. For Syst. 2013;22(2):320-39. Based on a survey of experts from around the world, this review presented guidelines for assisting the developers and users of forest management decision support systems.

16. Gordon SN, Floris A, Boerboom L, Lämås T, Eriksson LO, Nieuwenhuis M, et al. Studying the use of forest management decision support systems: An initial synthesis of lessons learned from case studies compiled using a semantic wiki. Scand J For Res. 2014;29(Supplement 1):44-55

17. Nilsson M, Wästerlund DS, Wahlberg O, Eriksson LO. Forest planning in a Swedish company - a knowledge management analysis of forest information. Silva Fenn. 2012;46(5):717-31.

18. Vacik H, Torresan C, Hujala T, Khadka C, Reynolds K. The role of knowledge management tools in supporting sustainable forest management. For Syst. 2013;22(3):442-55.

19. Hujala T, Khadka C, Wolfslehner B, Vacik H. Supporting problem structuring with computer-based tools in participatory forest planning. For Syst. 2013;22(2):270-81.

20. Segura M, Ray D, Maroto C. Decision support systems for forest management: A comparative analysis and assessment. Comput Electron Agric. 2014;101:55-67.
21. Diaz-Balteiro L, González-Pachón J, Romero C. Goal programming in forest management: Customising models for decisionmaker's preferences. Scand J For Res. 2013;28(2):166-73.

22. Bettinger P, Siry J, Merry K. Forest management planning issues posed by climate change. For Sci Technol. 2013;9(1):9-19. This review described various approaches forest planners might pursue when developing strategic or tactical forest plans that acknowledge potential changes in forests or the landscape as a result of potential changes in climate

23. Keenan RJ. Climate change impacts and adaptation in forest management: A review. Ann For Sci. 2015;72:145-67.

24. Duerr WA, Fedkiw J, Guttenberg S. Financial maturity: A guide to profitable timber growing. Washington, DC: U.S. Department of Agriculture; 1956. Technical Bulletin 1146.

25. Kotamaa E, Tokola T, Maltamo M, Packalén P, Kurttila M, Mäkinen A. Integration of remote sensing-based bioenergy inventory data and optimal bucking for stand-level decision making. Eur J For Res. 2010;129:875-86.

26. Bettinger P, Tang M. Tree-level optimization for structure-based forest management based on the species mingling index. Forests. 2015;6(4):1121-44.

27.• Nieuwenhuis M. Terminology of forest management. Terms and definitions in English. Revised edition. Vienna: International Union of Forest Research Organizations; 2010. This dictionary of forestry terms presented a world-wide perspective on the language and definitions used in the forestry field, and should be viewed as a basic reference for forestry professionals.

28. Bullard SH. Financial maturity of timber and maximum net present values. Resour Manag Optim. 1985;3(3):219-25.

29. Niinimäki S, Tahvonen O, Mäkelä A. Applying a process-based model in Norway spruce management. For Ecol Manag. 2012;265:102-15.

30. Ahtisoski A, Salminen H, Ojansuu R, Hynynen J, Kärkkäinenen $\mathrm{K}$, Haapanen M. Optimizing stand management involving the effect of genetic gain: Preliminary results for Scots pine in Finland. Can J For Res. 2013;43:299-305.

31. Ahtisoski A, Salminen H, Hökkä H, Kojola S, Penttilä T. Optimising stand management on peatlands: The case of northern Finland. Can J For Res. 2012;42:247-59.

32. Petrášek S, Perez-Garcia J. A Monte Carlo methodology for solving the optimal timber harvest problem with stochastic timber and carbon prices. Math Comput For Nat Resour Sci. 2010;2(2):6777.

33. Eriksson LO, Backéus S, Garcia F. Implications of growth uncertainties associated with climate change for stand management. Eur J For Res. 2012;131:1199-209.

34. Pukkala T, Lahde E, Laiho O. Optimizing the structure and management of uneven-sized stands of Finland. Forestry. 2010;83(2): 129-42.

35. Bayat M, Pukkala T, Namiranian M, Zobeiri M. Productivity and optimal management of the uneven-aged hardwood forests of Hyrcania. Eur J For Res. 2013;132:851-64.

36. Hyytiäinen $\mathrm{K}$, Haight R. Evaluation of forest management systems under risk of wildfire. Eur J For Res. 2010;129:909-19.

37. Zhou M, Buongiorno J. Effects of stochastic interest rates in decision making under risk: A Markov decision process model for forest management. For Policy Econ. 2011;13:402-10.

38. Hofstad O, Araya M. Optimal wood harvest in miombo woodland considering REDD+ payments - A case study at Kitulangalo Forest Reserve, Tanzania. For Policy Econ. 2015;51:9-16.

39. Tahvonen O, Pukkala T, Laiho O, Lähde E, Niinimäki S. Optimal management of uneven-aged Norway spruce stands. For Ecol Manag. 2010;260:106-15.

40. López Torres L, Ortuño Pérez S, Martínez Fernández A, Fullana Belda C. Estimating the optimal rotation age of Pinus nigra in the 
Spanish Iberian System applying discrete optimal control. For Syst. 2010;19(3):306-14.

41. Buongiorno J, Halvorsen EA, Bollandsås OM, Gobakken T, Hofstad O. Optimizing management regimes for carbon storage and other benefits in uneven-aged stands dominated by Norway spruce, with a derivation of the economic supply of carbon storage. Scand J For Res. 2012;27:460-73.

42. Schou E, Meilby H. Transformation of even-aged European beech (Fagus sylvatica L.) to uneven-aged management under changing growth conditions caused by climate change. Eur J For Res. 2013;132:777-89.

43. Rämö J, Tahvonen $\mathrm{O}$. Economics of harvesting uneven-aged forest stands in Fennoscandia. Scand J For Res. 2014;29(8):777-92.

44. Köthke M, Dieter M. Effects of carbon sequestration rewards on forest management - An empirical application of adjusted Faustmann Formulae. For Policy Econ. 2010;12:589-97.

45. Navarrete E. Modeling optimal pine stands harvest under stochastic wood stock and price in Chile. For Policy Econ. 2012;15:54-9.

46. Halbritter A, Deegen P. A combined economic analysis of optimal planting density, thinning and rotation for an even-aged forest stand. For Policy Econ. 2015;51:38-46.

47. De-Miguel S, Pukkala T, Yeșil A. Integrating pine honeydew honey production into forest management optimization. Eur J For Res. 2014;133:423-32.

48. Pukkala T. Optimizing forest management in Finland with carbon subsidies and taxes. For Policy Econ. 2011;13:425-34.

49. Möykkynen T, Pukkala T. Optimizing the management of Norway spruce and Scots pine mixtures on a site infected by Heterobasidion coll. Scand J For Res. 2010;25:127-37.

50. Pukkala T, Kellomäki S. Anticipatory vs adaptive optimization of stand management when tree growth and timber prices are stochastic. Forestry. 2012;85(4):463-72.

51. Nghiem N. Optimal rotation age for carbon sequestration and biodiversity conservation in Vietnam. For Policy Econ. 2014;38: 56-64.

52. Xin J, Xiujuan W. Optimal harvest decision model for the forest: A new analysis framework to Chinese forestry economic policy. Sci Silvae Sin. 2013;49(9):178-85.

53. Raymer AK, Gobakken T, Solberg B. Optimal forest management with carbon benefits included. Silva Fenn. 2011;45(3):395-414.

54. Goetz R-U, Hritonenko N, Mur RJ, Xabadia A, Yatsenko Y. Forest management and carbon sequestration in size-structured forests: The case of Pinus sylvestris in Spain. For Sci. 2010;56(3):242-56.

55. Duduman G. A forest management planning tool to create highly diverse uneven-aged stands. Forestry. 2011;84(3):301-13.

56. Ferreira L, Constantino MF, Borges JG, Garcia-Gonzalo J. A stochastic dynamic programming approach to optimize short-rotation coppice systems management scheduling: An application to eucalypt plantations under wildfire risk in Portugal. For Sci. 2012;58(4):353-65.

57. Huu-Dung N, Yeo-Chang Y. Optimum harvesting time and clone choices for eucalyptus growers in Vietnam. For Policy Econ. 2012;15:60-9.

58. Nordström E-M, Holmström H, Öhman K. Evaluating continuous cover forestry based on the forest owner's objectives by combining scenario analysis and multiple criteria decision analysis. Silva Fenn. 2013; 47(4), article id 1046.

59. Garcia-Gonzalo J, Borges JG, Palma JHN, ZubizarretaGerendiain A. A decision support system for management planning of Eucalyptus plantations facing climate change. Ann For Sci. 2014;71:187-99.

60. Wei Y, Bevers M, Nguyen D, Belval E. A spatial stochastic programming model for timber and core area management under risk of fires. For Sci. 2014;60(1):85-96.
61. Wikström P, Edenius L, Elfving B, Eriksson LO, Lämas T, Sonesson J, et al. The Heureka forestry decision support system: An overview. Math Comput For Nat Resour Sci. 2011;3(2):8794.

62. Korosuo A, Wikström P, Öhman K, Eriksson LO. In integrated MCDA software application for forest planning: A case study in southwestern Sweden. Math Comput For Nat Resour Sci. 2011;3(2):75-86.

63. Garcia-Gonzalo J, Palma JHN, Freire JPA, Tome M, Mateus R, Rodriguez LCE, et al. A decision support system for a multi stakeholder's decision process in a Portuguese National Forest. For Syst. 2013;22(2):359-73

64. Strimbu BM, Innes JL, Strimbu VF. A deterministic harvest scheduler using perfect bin-packing theorem. Eur J For Res. 2010;129:961-74.

65. Costa A, Oliveira AC, Vidas F, Borges JG. An approach to cork oak forest management planning: A case study in southwestern Portugal. Eur J For Res. 2010;129:233-41.

66. Kangas A, Nurmi M, Rasinmäki J. From a strategic to a tactical forest management plan using a hierarchic optimization approach. Scand J For Res. 2014;29(Supplement 1):154-65.

67. Fonseca TF, Cerveira A, Mota A. An integer programming model for a forest harvest problem in Pinus pinaster stands. For Syst. 2012;21(2):272-83.

68. Kašpar J, Marušák R, Hlavatý R. A forest planning approach with respect to the creation of overmature reserved areas in managed forests. Forests. 2015;6:328-43.

69. Öhman K, Edenius L, Mikusiński G. Optimizing spatial habitat suitability and timber revenue in long-term forest planning. Can J For Res. 2011;41:543-51.

70. Flisberg P, Frisk M, Rönnqvist M. Integrated harvest and logistic planning including road upgrading. Scand J For Res. 2014;29(Supplement 1):195-209.

71. Öhman K, Eriksson LO. Aggregating harvest activities in long term forest planning by minimizing harvest area perimeters. Silva Fenn. 2010;44(1):77-89.

72. Moreira JMMAP, Rodriguez LCE, Caixeta-Filho JV. An optimization model to integrate forest plantations and connecting corridors. For Sci. 2013;59(6):661-9.

73. Tóth SF, McDill ME, Könnyü N, George S. Testing the use of lazy constraints in solving area-based adjacency formulations of harvest scheduling models. For Sci. 2013;59(2):157-76.

74. Tóth SF, McDill ME, Könnyü N, George S. A strengthening procedure for the path formulation of the area-based adjacency problem in harvest scheduling models. Math Comput For Nat Resour Sci. 2012;4(1):27-49.

75. Manning PJ, McDill ME. Optimal parameter settings for solving harvest scheduling models with adjacency constraints. Math Comput For Nat Resour Sci. 2012;4(1):16-26.

76. Li R, Bettinger P, Weiskittel A. Comparisons of three different methods used to generate forest landscapes for spatial harvest scheduling problems with adjacency constraints. Math Comput For Nat Resour Sci. 2010;2(1):53-60.

77. Borges P, Bergseng E, Eid T. Adjacency constraints in forestry - A simulated annealing approach comparing different candidate solution generators. Math Comput For Nat Resour Sci. 2014;6(1):1125 .

78. Chen Y-T, Chang C-T. Multi-coefficient goal programming in thinning schedules to increase carbon sequestration and improve forest structure. Ann For Sci. 2014;71:907-15.

79. Hahn WA, Härtl F, Irland LC, Kohler C, Moshammer R, Knoke T. Financially optimized management planning under risk aversion results in even-flow sustained timber yield. For Policy Econ. 2014;42:30-41.

80. Mäkelä H, Hirvelä H, Nuutinen T, Kärkkäinen L. Estimating forest data for analyses of forest production and utilization 
possibilities at local level by means of multi-source National Forest Inventory. For Ecol Manag. 2011;262:1345-59.

81. Hennigar CR, Wilson JS, MacLean DA, Wagner RG. Applying a spruce budworm decision support system to Maine: Projecting spruce-fir volume impacts under alternative management and outbreak scenarios. J For. 2011;109:332-42.

82. Ponce YR, Ruiz-Tagle M, García-Robredo F, Gutiérrez J. Multiple-use forest planning model for second-growth forests of roble-raulí-coihue (genus Nothofagus). Eur J For Res. 2010;129: 947-60.

83. Borges JG, Garcia-Gonzalo J, Bushenkov V, McDill ME, Marques S, Oliveira MM. Addressing multicriteria forest management with Pareto frontier methods: An application in Portugal. For Sci. 2014;60(1):63-72.

84. Bergseng E, Ask JA, Framstad E, Gobakken T, Solberg B, Hoen HF. Biodiversity protection and economics in long term boreal forest management - A detailed case for the valuation of protection measures. For Policy Econ. 2012;15:12-21.

85. Lappi J, Lempinen R. A linear programming algorithm and software for forest-level planning problems including factories. Scand J For Res. 2014;29(Supplement 1):178-84.

86. Başkent EZ, Küçüker DM. Incorporating water production and carbon sequestration into forest management planning: A case study in Yalnızçam planning unit. For Syst. 2010;19(1):98-111.

87. Aldea J, Martínez-Peña F, Diaz-Balteiro L. Integration of fungal production in forest management using a multi-criteria method. Eur J For Res. 2012;131:1991-2003.

88. Başkent EZ, Keleș S, Kadıŏulları A. Challenges in developing and implementing a decision support systems (ET AP) in management planning: A case study in Honaz and Ibrad, Turkey. Scand J For Res. 2014;29(Supplement 1):121-31.

89. Maroto C, Segura M, Ginestar C, Uriol J, Segura B. Sustainable forest management in a Mediterranean region: Social preferences. For Syst. 2013;22(3):546-58.

90. Aldea J, Martínez-Peña F, Romero C, Diaz-Balteiro L. Participatory goal programming in forest management: An application integrating several ecosystem services. Forests. 2014;5: 3352-71.

91. Silva M, Weintraub A, Romero C, del la Maza C. Forest harvesting and environmental protection based on the goal programming approach. For Sci. 2010;56(5):460-72.

92. Chen Y-T, Zheng C, Chang C-T. 3-level MCGP: An efficient algorithm for MCGP in solving multi-forest management problems. Scand J For Res. 2011;26:457-65.

93. Marinescu MV, Maness TC. A hierarchical timber allocation model to analyze sustainable forest management decisions. Math Comput For Nat Resour Sci. 2010;2(2):117-34.

94. Zengin H, Asan Ü, Destan S, Ünal ME, Yeșil A, Bettinger P, et al. Modeling harvest scheduling in multifunctional planning of forests for longterm water yield optimization. Nat Resour Model. 2015;28(1):59-85.

95. Zhai W, Zhao Y, Lian X, Yang M, Lu F. Management planning of fast-growing plantations based on a bi-level programming model. For Policy Econ. 2014;38:173-7.

96. Konoshima M, Albers HJ, Montgomery CA, Arthur JL. Optimal spatial patterns of fuel management and timber harvest with fire risk. Can J For Res. 2010;40:95-108.

97. Fotakis DG, Sidiropoulos E, Myronidis D, Ioannou K. Spatial genetic algorithm for multi-objective forest planning. For Policy Econ. 2012;21:12-9.

98. Kangas A, Hartikainen M, Miettinen K. Simultaneous optimization of harvest schedule and measurement strategy. Scand J For Res. 2014;29(Supplement 1):224-33.

99. Soltani A, Eid T, Hofstad O. Optimizing management of goats and oak trees for sustainability and community's welfare: A case study from Zagros, Iran. Scand J For Res. 2015;30(1):49-59.
100. Neuner S, Beinhofer B, Knoke T. The optimal tree species composition for a private forest enterprise applying the theory of portfolio selection. Scand J For Res. 2013;28:38-48.

101. Sims C. Optimal timing of salvage harvest in response to a stochastic infestation. Nat Resour Model. 2011;24(3):383-408.

102. Rode R, Leite HG, da Silva ML, Ribeiro CAAS, Binoti DDHB. The economics of optimal management regimes of eucalyptus plantations: A case study of forestry outgrower schemes in Brazil. For Policy Econ. 2014;44:26-33.

103. Bizikova L, Krcmar E. Integrated scenario planning and multicriteria decision analysis framework with application to forest planning. Open J For. 2015;5:139-53.

104. Colombo SJ, Chen J, Ter-Mikaelian MT, McKechnie J, Elkie PC, MacLean HL, et al. Forest protection and forest harvest as strategies for ecological sustainability and climate change mitigation. For Ecol Manag. 2012;281:140-51.

105. Hossain SMY, Robak EW. A forest management process to incorporate multiple objectives: A framework for systematic public input. Forests. 2010;1:99-113.

106. Savage DW, Martell DL, Wotton BM. Forest management strategies for dealing with fire-related uncertainty when managing two forest seral stages. Can J For Res. 2011;41:309-20.

107. Salehi A, Eriksson LO. A model for management of mixed coppice stands in semiarid Persian oak forests. Math Comput For Nat Resour Sci. 2010;2(1):20-9.

108. Kärkkäinen L, Nuutinen T, Hirvelä H, Mäkelä H. Effects of administrative land-use and technical land-form constraints on timber production at the landscape level. Scand J For Res. 2011;26: $120-7$.

109. Hauer G, Cumming S, Schmiegelow F, Adamowicz W, Weber M, Jagodzinski R. Tradeoffs between forestry resource and conservation values under alternate policy regimes: A spatial analysis of the western Canadian boreal plains. Ecol Model. 2010;221:2590-603.

110. Marshalek EC, Ramage BS, Potts MD. Integrating harvest scheduling and reserve design to improve biodiversity conservation. Ecol Model. 2014;287:27-35.

111. González-Olabarria J-R, Pukkala T. Integrating fire risk considerations in landscape-level forest planning. For Ecol Manag. 2011;261:278-87.

112. Heinonen T, Pukkala T, Ikonen V-P, Peltola H, Gregow H, Venäläinen A. Consideration of strong winds, their directional distribution and snow loading in wind risk assessment related to landscape level forest planning. For Ecol Manag. 2011;261:710 9.

113. U.S. Forest Service. Revised land and resource management plan, George Washington National Forest. Atlanta, Georgia: US Department of Agriculture, Forest Service, Region 8; 2014. R8MB 143 A

114. California Department of Forestry and Fire Protection. Jackson Demonstration State Forest management plan. Sacramento: California Department of Forestry and Fire Protection; 2008.

115. Ince PJ. Faustmann and the forestry tradition of outcome-based performance measures. In: Chang SJ, editor. Proceedings of the international symposium 150 Years of the Faustmann formula: Its consequences for forestry and economics in the past, present, and future. Baton Rouge: Louisiana State University, School of Forestry, Wildlife, and Fisheries; 1999. p. 243-69.

116. Hool JN. A dynamic programming - Markov chain approach to forest production control. For Sci Monogr. 12.

117. Amidon EL, Akin GS. Dynamic programming to determine optimum levels of growing stock. For Sci. 1968;14(3):287-91.

118. Valsta LT. A scenario approach to stochastic anticipatory optimization in stand management. For Sci. 1992;38(2):430-47.

119. Boston K, Bettinger P. An economic and landscape evaluation of the green-up rules for California, Oregon, and Washington (USA). For Policy Econ. 2006;8(3):251-66. 
120. Boston K, Bettinger P. The economic impact of green-up constraints in the southeastern United States. For Ecol Manag. 2001;145(3):191-202.

121. Siry JP, Bettinger P, Merry K, Grebner DL, Boston K, Cieszewski C, editors. Forest Plans of North America. New York: Academic Press; 2015.

122. Bettinger $\mathrm{P}$, Chung $\mathrm{W}$. The key literature of, and trends in, forestlevel management planning in North America, 1950-2001. Int For Rev. 2004;6:40-50.
123. Myllyviita T, Hujala T, Kangas A, Eyvindson K, Sironen S, Leskinen P, et al. Mixing methods - assessment of potential benefits for natural resources planning. Scand J For Res. 2014;29(Sup 1):20-9.

124. Bettinger P, Boston K, Siry JP, Grebner DL. Forest management and planning. New York: Academic Press. 